\title{
Video Article \\ Therapeutic Effectiveness of a Dietary Supplement for Management of Halitosis in Dogs
}

\author{
Alessandro Di Cerbo ${ }^{1}$, Federica Pezzuto ${ }^{2}$, Sergio Canello ${ }^{3}$, Gianandrea Guidetti ${ }^{3}$, Beniamino Palmieri ${ }^{1,4}$ \\ ${ }^{1}$ Department of Surgery and Surgical Specialties, Azienda Ospedaliero-Universitaria Policlinico di Modena \\ ${ }^{2}$ Department of Clinical Microbiology, Universtity of Modena and Reggio Emilia \\ ${ }^{3}$ Sanypet S.p.a \\ ${ }^{4}$ AIRMO Center Milan
}

Correspondence to: Alessandro Di Cerbo at alessandro811@hotmail.it

URL: https://www.jove.com/video/52717

DOI: doi: $10.3791 / 52717$

Keywords: Medicine, Issue 101, halitosis, dietary supplement, dogs, portable gas chromatograph, human, clinical practice

Date Published: 7/6/2015

Citation: Di Cerbo, A., Pezzuto, F., Canello, S., Guidetti, G., Palmieri, B. Therapeutic Effectiveness of a Dietary Supplement for Management of Halitosis in Dogs. J. Vis. Exp. (101), e52717, doi:10.3791/52717 (2015).

\section{Abstract}

Halitosis is a common complaint involving social and communicational problems in humans and also affects the pet-owner relationship. In this randomized placebo-controlled crossover clinical evaluation, we assessed the effectiveness of a dedicated dietary supplement to improve chronic halitosis in 32 dogs of different breeds and ages. This protocol describes how to evalute the presence of oral volatile suphur compunds, e.g. methyl mercaptan, hydrogen sulfide and dimethyl sulfide, by means of a portable gas chromatograph device coupled with a syringe, which was used to collect the breath, and a dedicated software, which allows the operator to monitor each compound concentration during each measurement, in a relatively short time $(8 \mathrm{~min})$

A significant modification of halitosis parameters was observed after 30 days since the beginning of treatment $(p<0.05)$, while a long-lasting effect was still observed even 20 days after the suspension of the treatment. Portable gas chromatograph, which is also widely used in clinical practice, can be therefore used to confirm and control halitosis in humans and animals. Even though human and animal species present some differences, this innovative and alternative therapy for halitosis management might be extended to human clinical practice as an adjuvant dietary approach.

\section{Video Link}

The video component of this article can be found at https://www.jove.com/video/52717/

\section{Introduction}

Oral malodor, also known by the term halitosis, is a common complaint which causes embarrassment in interpersonal social relationships ${ }^{1}$ as much as body malodor ${ }^{2}$. Although most epidemiological data on oral malodor is limited in accuracy and sensitivity due to a subjective selfestimation, studies report that $30-50 \%$ of the population is affected by this pathology ${ }^{3-6}$. Some studies have also evidenced that it is more prevalent in men than in women regardless of age with a ratio $3: 1$ and the ratio is slightly higher in people over 20 years ${ }^{7}$.

Halitosis can be staged depending on its etiology: type 1 (oral), type 2 (airway), type 3 (gastroesophageal), type 4 (blood-borne) and type 5 (subjective); however, it has been hypothesized that halitosis could be potentially considered the sum of these types in any combination, superimposed on the physiologic odour present in health (Type 0$)^{8,9}$. Scully et al., who widely described and characterized aetiopathogenesis and management of halitosis, reported that in some patients it has an extra-oral aetiology and, in a few of them, metabolic anomalies are involved ${ }^{10}$. The authors pointed out that volatile sulphur compounds (VSC) and some predisposing factors, e.g. poor oral hygiene, hyposalivation, dental appliances, gingival and periodontal disease and mucosal disease, are mainly responsible for the malodor. Further, they proposed oral health improvement, anti-malodor therapies and malodor counteractives as a basic conventional approach. Moreover, they also proposed the use of probiotics and vaccines against malodor causing bacteria.

Human and animal companions, i.e. cats and dogs, can be affected by food-related adverse reactions which can involve several systems such as the gastroenteric, cutaneous, otological, ocular, urinary and respiratory systems ${ }^{11-13}$. However, several animal studies have pointed out that the nasal chamber is one of most involved systems where tartar ${ }^{14}$, stomatitis ${ }^{15}$, and halitosis ${ }^{16}$ are quite often present. Furthermore, bacteria that cause halitosis can be transmitted from animal companions to humans ${ }^{17}$. Iwanicka-Grzegorek quantified sulphur compounds and low molecular mass amines in saliva from 84 patients suffering from halitosis and 40 healthy controls. More than $80 \%$ of patients belonging to the halitosis group reported having pets in childhood $(P<0.001)$ and over $70 \%$ still owned a pet $(P<0.001)$.

Therefore nutrition can be used to manage halitosis. Moreover, nutrition plays a pivotal role in tooth development, oral and gum tissue integrity, bone resistance and even dental and oral disease management ${ }^{18}$. Based on such considerations, at the Italian Association for Oncological 
Research Disease (AIRMO) Center, we run a randomized placebo-controlled crossover clinical evaluation involving 32 dogs suffering from halitosis in order to investigate the efficacy of a dietary supplement vs. a commercially available pet food.

\section{Protocol}

This clinical evaluation was planned accordingly with the European legislation (86/609/EU) and the experimental protocol was approved by the Ethics and Welfare Animal Committee of the AIRMO Research Center (Milan, Italy).

\section{Dogs and Food Selection}

1. Randomly divide 32 dogs of different breeds ( $7.01 \pm 0.20$ year [mean \pm standard error of mean (SEM)]; $34.05 \pm 1.47 \mathrm{Kg}$ [mean $\pm \mathrm{SEM}$ ]; 12 males and 20 females) suffering from chronic halitosis into 2 groups, providing them with either the dietary supplement or the placebo over a period of 30 days.

2. Ensure that each dog receives the appropriate dose of dietary supplement or placebo based on the animal's weight in kilograms, according to the manufacturer's instructions. (Table 1).

3. After a 30 day treatment, ensure that both groups have a 10 day wash out, where all animals are fed with placebo. At the end of the wash out period, the feeding regimen for the two groups are reversed such that the control group receives the dietary supplement for another 30 days and the treatment group receives the placebo.

4. Two veterinary inspections performed on the dogs in both groups, one before and one after the 30 day treatment.

\section{The Gas Chromatograph}

Note: The gas chromatograph is a portable device which measures the volatile sulphur compounds (VSC), hydrogen sulfide, methyl mercaptan, and dimethyl sulfide, which are the major causative factors of halitosis, providing information about the concentration of each gas measured Measuring each VSC helps to identify the cause of halitosis and assess treatment efficacy.

1. Using the procedure outlined in sections 3 and 4, examine volatile sulphur compounds (VSC) before treatment with the dietary supplement (time 0), 10 days post-treatment (time 10), 20 days post-treatment (time 20) and at the end of treatment (time 30).

\section{Gas Chromatograph Setting}

1. Turn on the main switch at the back of the unit. Note: The initial screen displays the word "MEASUREMENT MODE".

2. Press the ENTER key to select MEASUREMENT MODE.

Note: WAIT is displayed on the screen and the standby time required to stabilize the measuring device is displayed next to the word "COUNTER". When the standby time has come to an end, the device is automatically ready to measure and the READY indicator lamp turns on.

\section{Dogs Breath Sampling and Analysis}

1. Run the Data Manager software.

2. Click "Measurement" after confirming that "Current status" is "Ready to measure"

3. Enter ID and click "Select". Note: A message is displayed at the upper right-hand corner of the window.

1. If the message displayed is "Inject oral gas", start the measurement.

2. If the message displayed is "The device is being ready", then wait.

4. By means of a $1 \mathrm{ml}$ disposable syringe, collect the breath from the dog's mouth by placing the syringe in the dog's labial commissure, slowly pulling the plunger and removing the syringe from the dog's mouth .

5. Adjust the volume of the syringe to $1 \mathrm{ml}$

6. Attach the supplied needle to the end of the syringe and, after opening the lid, eject the sample into the inlet on the device main unit by pushing the plunger.

Note: Measurements start automatically and the READY indicator lamp goes off. Measurement is completed in 8 min and the result is automatically displayed (display can be changed to "Chromatogram"). The Judgment window appears upon completing the measurement. Measurement history and measured data can be displayed .

7. Push ENTER to store the results into the unit. Note: Data are expressed in standard units of parts per billion $(\mathrm{ppb})$ and/or $\mathrm{ng} / 10 \mathrm{ml}$.

8. Then wait $1 \mathrm{~min}$ to stabilize the device and perform a new measurement. Note: At the end of this time, the lamp turns on meaning that the device is ready.

\section{Representative Results}

Both placebo and dietary supplement were adjusted in order to provide similar nutritional and caloric intake and to satisfy the nutritional requirement of adult dogs, in particular. Their analytical composition was: crude protein $26 \%$, crude oils and fats $13 \%$, crude fiber $2.5 \%$, crude ash $8 \%$ and Metabolized Energy (EM) $3464 \mathrm{kcal} / \mathrm{kg}$. Metabolized energy was calculated according to the Nutritional Guidelines for complete and complementary pet food for cats and dogs by The European Pet Food Industry Federation. Placebo was composed of dehydrated chicken meat, rice, animal fat, dehydrated eggs, oat, dry beet pulp, flax seeds, hydrolysed animal proteins, fish oil, vegetable oil, calcium carbonate, dry yeast beer, monocalcium phosphate, sodium chloride. Dietary supplement differed from the placebo for the presence of active substances contained 
in special heart-shaped cold pressed tablets (European patent n. EP 2526781) included in the complete food in a percentage of 6-7\%, and for the protein source, fish meal instead chicken meal. Tablets contained propolis $(0.0161 \%)$, Salvia officinalis $(0.0087 \%)$, egg albumen (lysozyme $0.0078 \%)$, dehydrated orange extract (bioflavonoids $0.0077 \%)$, Thymus vulgaris $(0.0127 \%)$, Ribes nigrum $(0.0040 \%)$.

Data were analyzed, presented as the means \pm standard error of the mean and checked for normality using the D'Agostino-Pearson normality test. A multiple $t$-test was used to compare changes in VSCs score at follow-up versus baseline for each treatment modality.

Figure 1A shows a significant decrease in hydrogen sulfide concentration in treated animals, from a baseline value of $0.43 \mathrm{ng} / \mathrm{ml}$ to $0.06 \mathrm{ng} / \mathrm{ml}$, after 30 days treatment. Figure 1B shows a significant decrease of methyl mercaptan concentration in treated animals, from a baseline value of $0.30 \mathrm{ng} / \mathrm{ml}$ to $0.06 \mathrm{ng} / \mathrm{ml}$, after 30 days treatment. Figure 1C shows a significant decrease in dimethyl sulfide concentration in treated animals, from a baseline value of $0.28 \mathrm{ng} / \mathrm{ml}$ to $0.13 \mathrm{ng} / \mathrm{ml}$, after 30 days treatment.

Figure 2A shows a significant decrease in hydrogen sulfide concentration, from a baseline value of $0.37 \mathrm{ng} / \mathrm{ml}$ to $0.10 \mathrm{ng} / \mathrm{ml}$, after 20 days treatment. In Figure 2B a similar trend is observed also for methyl mercaptan which shows a significant decrease of the compound concentration, from a baseline value of $0.24 \mathrm{ng} / \mathrm{ml}$ to $0.05 \mathrm{ng} / \mathrm{ml}$, after 30 days treatment. As to dimethyl sulfide, Figure 2C, a significant decrease of the compound concentration, from a baseline value of $0.32 \mathrm{ng} / \mathrm{ml}$ to $0.11 \mathrm{ng} / \mathrm{ml}$, was observed after 30 days treatment.

\begin{tabular}{|l|l|}
\hline BODY WEIGHT $(\mathrm{Kg})$ & DIETARY SUPPLEMENT AMOUNT PER DAY $(\mathrm{g})$ \\
\hline $1-10$ & $30-180$ \\
\hline $11-20$ & $190-300$ \\
\hline $21-35$ & $310-455$ \\
\hline $36-50$ & $465-595$ \\
\hline
\end{tabular}

Table 1: Daily Amount of Food Provided to Dogs. 

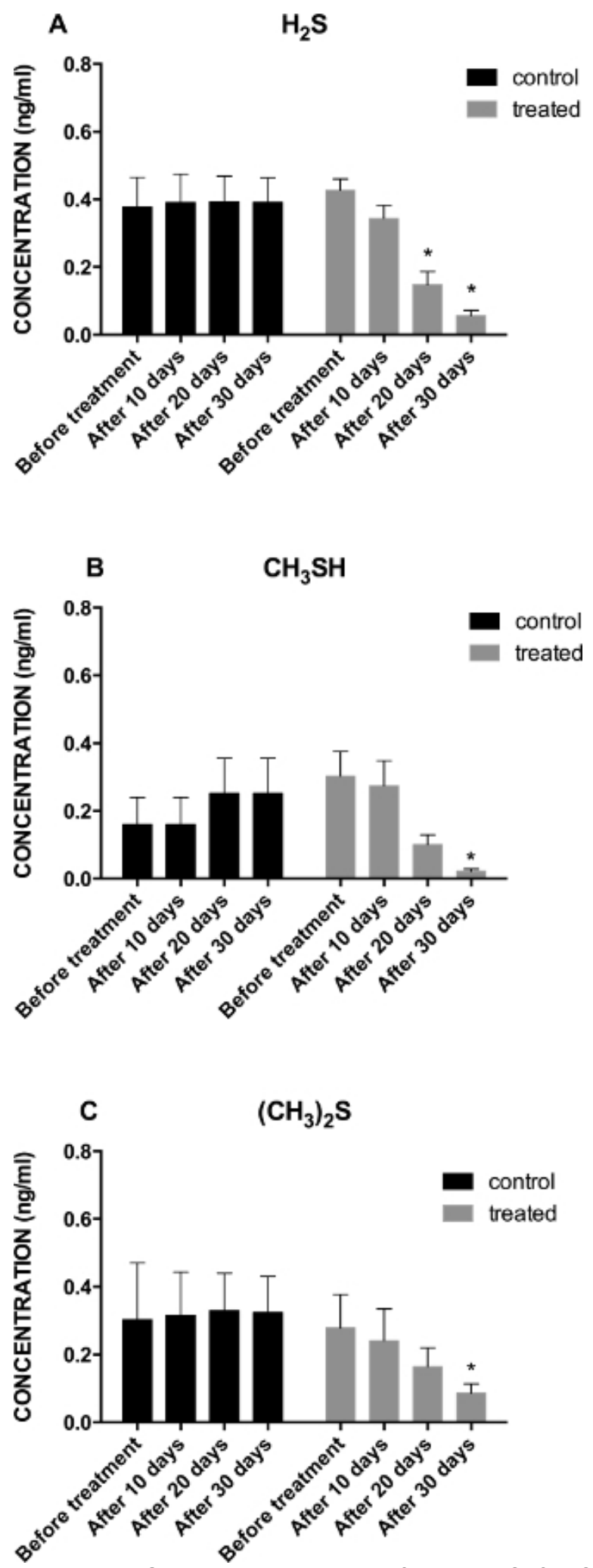

Figure 1: (A) Graphical Representation of Hydrogen Sulfide Concentration Trend in Treated $(n=16)$ vs Control $(n=16)$ Group During the 30 Days Treatment Period; * $<$ 0.05; (B) Graphical Representation of Methyl Mercaptan Concentration Trend in Treated $(n=16)$ vs Control $(n=16)$ Group During the 30 Days Treatment Period; * $p<0.05$; (C) Graphical Representation of the Dimethyl Sulfide Concentration Trend in Treated ( $n=$ 16) vs Control $(n=16)$ Group During the 30 Days Treatment Period; * $p<0.05$. 

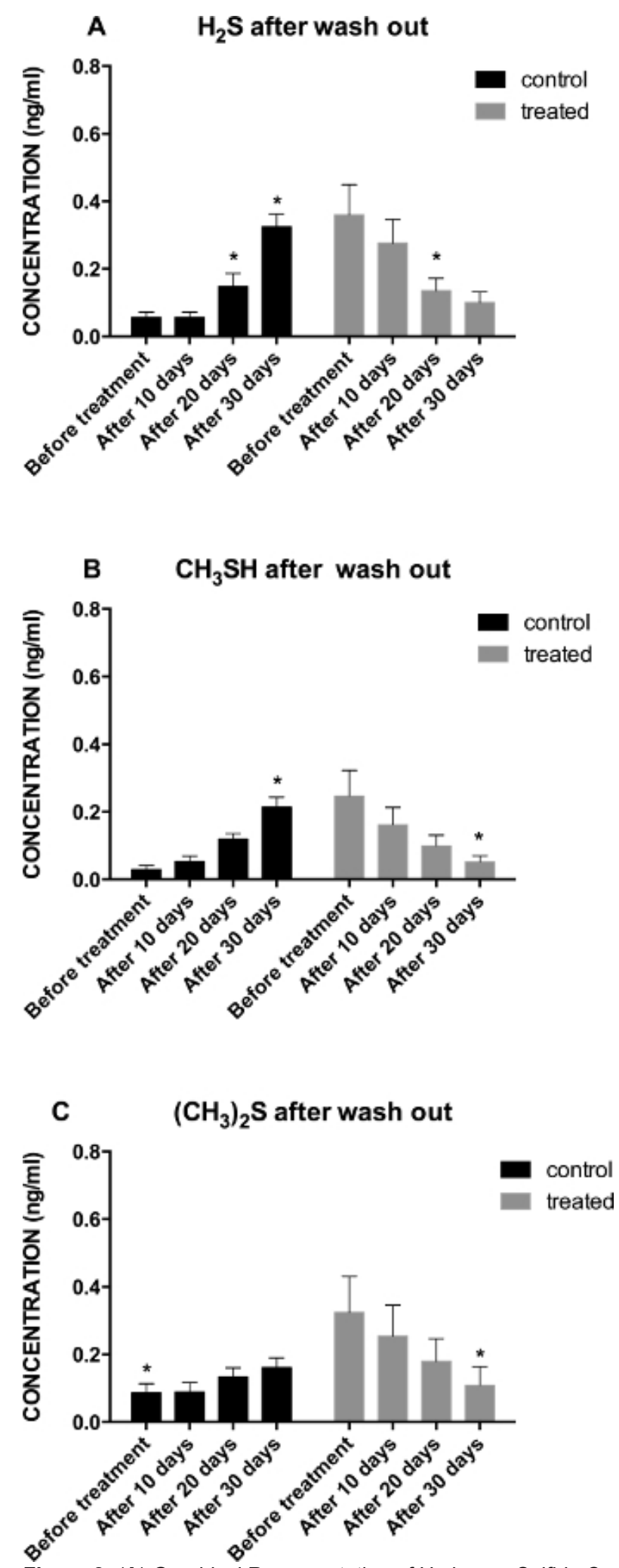

Figure 2: (A) Graphical Representation of Hydrogen Sulfide Concentration Trends in Treated ( $n=16)$ vs Control $(n=16)$ Group after the 10 Days Wash Out Period; * $<$ <.05; (B) Graphical Representation of Methyl Mercaptan Concentration Trend in Treated $(n=16) v . s$. Control $(n=$ 16) Group after the 10 Days Wash Out Period; ${ }^{*} p<0.05$; (C) Graphical Representation of Dimethyl Sulfide Concentration Trends in Treated $(n=$ 16) v.s. Control $(n=16)$ Group after the 10 Days Wash Out Period; * $p<0.05$ 


\section{Discussion}

Halitosis is a common problem in dogs, representing a psychosocial issue significantly affecting the pet-owner relationship ${ }^{19}$. Bad breath comes from microbial metabolism of both exogenous and endogenous protein substrates within the oral cavity ${ }^{20}$ which results in volatile sulphur compound production, and is worsened by other factors including acute necrotising ulcerative gingivitis, infected extraction site, debris under dental appliances, ulcers, tonsilloliths and low hygiene ${ }^{21-23}$. The main agents responsible for bad breath production are Gram-negative bacteria ${ }^{24}$ and their increase is related to a thickening of dental plaque ${ }^{25}$. Good oral hygiene along with specific diets can reduce the microbial load to the physiological level, reducing halitosis and avoiding gengivitis and periodontal diseases that have unpleasant effects on breath ${ }^{26}$.

This view is supported by our study showing that, after 10 days of dietary supplement intake, an overall improvement was observed in 29 out of 32 dogs $(90 \%)$ presenting a moderateto-severe malodor and, at the end of the evaluation, 19 out of 29 dogs (65\%) who achieved an improvement acquired a stabile physiological condition regarding VSCs concentration.

Our investigation broaches the very intriguing issue of the possible administration of a dietary supplement to dogs with breath malodor by basically introducing fish hydrolized proteins, sage, Ribes nigrum L., thyme, lysozyme, propolis, bioflavonoids and vitamin $C$ in the daily nutritional schedule. These compounds, widely used in traditional medicine, have been already proven effective both in vitro and in vivo.

Specifically, fish proteins were chosen on the basis of previous chromatographic studies which pointed out the presence of great amounts of hydrogen sulfide, methanethiol, ethanethiol, dimethyl sulfide, and ethylene sulfide in beef proteins ${ }^{27}$. Literature studies have also shown an antimicrobial activity of sage and Ribes nigrum L. against Streptoccocus mutans which is known to be one of the oral pathogens (along with Porphyromonas gingivalis and Candida albicans) responsible for oral malodor and dental caries formation ${ }^{28-30}$. Bioflavonoids and vitamin $\mathrm{C}$ have been recognized as both antiinflammatory and bacteriostatic agents limiting the growth of certain bacteria associated with periodontal diseases $^{31}$.

Regarding propolis and thyme, a reduction in malodor production from incubated whole saliva was demonstrated by Sterer et al. ${ }^{32}$ The bacteriostatic activity of propolis has been widely demontrated in literature, ranging from limiting the quantity of bacterial plaque ${ }^{33-37}$ to decreasing the tolerance of microorganisms to acid $\mathrm{pH}^{38}$, showing greater effectiveness than chlorhexidine gluconate solutions ${ }^{39}$. Moreover, propolis was proven effective in reducing teeth caries in rats limiting the number of microorganisms, slowing down synthesis of insoluble glucans, and glucosyltransferase activity ${ }^{40}$.

Our study presents some limitations such as the sensitivity of the instrument, if compared with other available techniques (e.g. bumpy WO3 hemitube nanostructure assisted by $\mathrm{O}_{2}$ plasma surface modification with functionalization of graphene-based material ${ }^{41}$, electrospun $\mathrm{SnO}_{2}$ nanofibers sensitized with reduced graphene oxide nanosheets ${ }^{42}$, benzoyl-DL-arginine-naphthylamide (BANA) test ${ }^{43}$, High Performance Liquid Chromatography (HPLC) ${ }^{44}$ and Solid-Phase Micro Extraction-Gas Chromatography/Mass Spectrometry (SPME-GC/MS ${ }^{45}$ ). On the other hand, the device employed in this study might allow, for instance, fast data collection to rapidly achieve an early diagnosis of viral hepatitis B, which is also characterized by elevated dimethile sulfide levels ${ }^{46}$ or to establish a state of systemic and/or respiratory disease (such as pneumonia, pulmonary emphysema and bronchitis) that are characterized by elevated hydrogen sulfide, methyl mercaptan and dimethyl sulfide levels ${ }^{47}$.

During the procedure we realized that the time available to collect the breath from a dog's mouth was slightly lower than that required (few seconds against $30 \mathrm{sec}$ suggested by the manufacturer). This problem was successfully overcome by repeating each measurement three times. A critical step during the experiment was breath collection. In order not to leave the dog with his mouth open for too long without damaging the syringe, we placed the syringe in the dog's labial commissure in order to safely collect the breath.

As observed in humans, further applications of this technique will be the prevention of breath-related diseases, i.e. systemic and respiratory, in dogs and more generally in pets. In summary, our study showed that the dietary supplement was effective in reducing chronic halitosis in dogs. Our results might be also in agreement with what is proposed by Porter et al., who hypothesized a possible interplay between halitosis and the gastrointestinal tract suggesting that a therapy for halitosis with oral origin might also have some effect upon gut bacteria composition which is known to be responsible, in some cases, for volatile sulphur compounds production ${ }^{48}$. Nevertheless, a dysbiosis might also occur after a massive use of antibiotics ${ }^{49}$, or meat derived from intensive livestocks and commonly used in most of animal and human food ${ }^{50,51}$.

\section{Disclosures}

The authors have nothing to disclose.

\section{Acknowledgements}

This review was not supported by grants. We thankSanypet S.p.a. (Padua, Italy) for kindly providing the dietary supplement and placebo used in this study. We also thank San Patrignano Community which kindly participated in the study by supplying all dogs.

\section{References}

1. Bosy, A. Oral malodor: philosophical and practical aspects. Journal (Canadian Dental Association). 63, 196-201 (1997).

2. Lee, S. S., Zhang, W., Li, Y. Halitosis update: a review of causes, diagnoses, and treatments). Journal of the California Dental Association. 35, 258-260 (2007).

3. Tessier, J. F., Kulkarni, G. V. Bad breath: etiology, diagnosis and treatment. Oral Health. 81, 19-22, 24 (1991).

4. Sanz, M., Roldan, S., Herrera, D. Fundamentals of breath malodour. The journal of Contemporary Dental Practice. 2, 1-17 (2001). 
5. Outhouse, T. L., Al-Alawi, R., Fedorowicz, Z., Keenan, J. V. Tongue scraping for treating halitosis. The Cochrane Database of Systematic Reviews. (2006).

6. Liu, X. N., et al. Oral malodor-related parameters in the Chinese general population. Journal of Clinical Periodontology. 33, 31-36 (2006).

7. Nadanovsky, P., Carvalho, L. B., Ponce de Leon, A. Oral malodour and its association with age and sex in a general population in Brazil. Oral Diseases. 13, 105-109 (2007).

8. Aydin, M., Harvey-Woodworth, C. N. Halitosis: a new definition and classification. British Dental Journal. 217, E1 (2014).

9. Porter, S., Fedele, S. Summary of: Halitosis: a new definition and classification. British Dental Journal. 217, 32-33 (2014).

10. Scully, C., Greenman, J. Halitology (breath odour: aetiopathogenesis and management. Oral Diseases. 18, 333-345 (2012).

11. Gaschen, F. P., Merchant, S. R. Adverse food reactions in dogs and cats. The Veterinary clinics of North America. Small Animal Practice. 41, 361-379 (2011).

12. Mandigers, P., German, A. J. Dietary hypersensitivity in cats and dogs. Tijdschrift voor Diergeneeskunde. 135-710 (2010).

13. Skypala, I. Adverse food reactions--an emerging issue for adults. Journal of the American Dietetic Association. 111, 1877-1891 (2011).

14. Larsen, J. Oral products and dental disease. Compendium (Yardley, PA). 32, E4 (2010).

15. Addie, D. D., Radford, A., Yam, P. S., Taylor, D. J. Cessation of feline calicivirus shedding coincident with resolution of chronic gingivostomatitis in a cat. The Journal of Small Animal Practice. 44, 172-176 (2003).

16. Simone, A., Jensen, L., Setser, C., Smith, M., Suelzer, M. Assessment of oral malodor in dogs. Journal of veterinary. 11, 71-74 (1994).

17. Iwanicka-Grzegorek, E., et al. Is transmission of bacteria that cause halitosis from pets to humans possible. Oral Diseases. 11, Suppl 1. 96-97 (2005)

18. Logan, E. I. Dietary influences on periodontal health in dogs and cats. The Veterinary Clinics of North America. Small Animal Practice. 36, 1385-1401 (2006).

19. Rawlings, J. M., Culham, N. Halitosis in dogs and the effect of periodontal therapy. The Journal of Nutrition. 128, 2715s-2716s (1998).

20. Weinberg, M. A., Wesphal, C., Froum, S. J., Palat, M., Schoor, R. Comprehensive Periodontics for the Dental Hygienist WEINBERG Mea A., WESTPHAL Cheryl, FROUM Stuart J., PALAT Milton, SCHOOR Robert: Librairie Lavoisier. 544, (2009).

21. Lee, P. P., Mak, W. Y., Newsome, P. The aetiology and treatment of oral halitosis: an update. Hong Kong medical journal = Xianggang yi xue za zhi / Hong Kong Academy of Medicine. 10, 414-418 (2004).

22. Laine, M. L., Slot, D. E., Danser, M. M. Halitosis. A common problem. Nederlands Tijdschrift voor Tandheelkunde. 118, 607-611 (2011).

23. Warrick, J. M., Inskeep, G. A., Yonkers, T. D., Stookey, G. K., Ewing, T. H. Effect of clindamycin hydrochloride on oral malodor, plaque, calculus, and gingivitis in dogs with periodontitis. Veterinary Therapeutics : Research in Applied Veterinary Medicine. 1, 5-16 (2000).

24. Nakano, Y., Yoshimura, M., Koga, T. Methyl mercaptan production by periodontal bacteria. International Dental Journal. 52, Suppl 3. 217-220 (2002).

25. Ritz, H. L. Microbial population shifts in developing human dental plaque. Archives of Oral Biology. 12, 1561-1568 (1967).

26. Culham, N., Rawlings, J. M. Oral malodor and its relevance to periodontal disease in the dog. Journal of Veterinary Dentistry. 15, 165-168 (1998).

27. Qvist, I. H., Von Sydow, E. C. F. Unconventional proteins as aroma precursors. Chemical analysis of the volatile compounds in heated soy, casein, and fish protein model systems. Journal of Agricultural and Food Chemistry. 22, 1077-1084 (1021).

28. Sterer, N., et al. Oral malodor reduction by a palatal mucoadhesive tablet containing herbal formulation. Journal of Dentistry. 36, 535-539 (2008).

29. Greenberg, M., Urnezis, P., Tian, M. Compressed mints and chewing gum containing magnolia bark extract are effective against bacteria responsible for oral malodor. J.Journal of Agricultural and Food Chemistry. 55, 9465-9469 (2007).

30. Ikuta, K., et al. Anti-viral and anti-bacterial activities of an extract of blackcurrants (Ribes nigrum L). Microbiology and Immunology. 56, 805-809 (2012).

31. Chatterjee, A., Saluja, M., Agarwal, G., Alam, M. Green tea: A boon for periodontal and general health. Journal of Indian Society of Periodontology. 16, 161-167 (2012).

32. Sterer, N., Rubinstein, Y. Effect of various natural medicinals on salivary protein putrefaction and malodor production. Quintessence International. 37, 653-658 (2006).

33. Steinberg, D., Kaine, G., Gedalia, I. Antibacterial effect of propolis and honey on oral bacteria. American Journal of Dentistry. 9, 236-239 (1996).

34. Koo, H., et al. In vitro antimicrobial activity of propolis and Arnica montana against oral pathogens. Archives of Oral Biology. 45, 141-148 (2000).

35. Botushanov, P. I., Grigorov, G. I., Aleksandrov, G. A. A clinical study of a silicate toothpaste with extract from propolis. Folia Medica. 43, 28-30 (2001).

36. Jeon, J. G., Rosalen, P. L., Falsetta, M. L., Koo, H. Natural products in caries research: current (limited) knowledge, challenges and future perspective. Caries Research. 45, 243-263 (2011).

37. Jafarzadeh Kashi, T. S., et al. Evaluating the In-vitro Antibacterial Effect of Iranian Propolis on Oral Microorganisms. Iranian Journal of Pharmaceutical Research : IJPR. 10, 363-368 (2011).

38. Duarte, S., et al. The influence of a novel propolis on mutans streptococci biofilms and caries development in rats. Archives of Oral Biology. 51, 15-22 (2006).

39. Ozan, F., et al. Effect of mouthrinse containing propolis on oral microorganisms and human gingival fibroblasts. European Journal of Dentistry. 1, 195-201 (2007).

40. Ikeno, K., Ikeno, T., Miyazawa, C. Effects of propolis on dental caries in rats. Caries Research. 25, $347-351$ (1991).

41. Choi, S. J., et al. Fast responding exhaled-breath sensors using WO3 hemitubes functionalized by graphene-based electronic sensitizers for diagnosis of diseases. ACS Applied Materials \& Interfaces. 6, 9061-9070 (2014).

42. Choi, S. J., et al. Selective detection of acetone and hydrogen sulfide for the diagnosis of diabetes and halitosis using $\mathrm{SnO}(2) \mathrm{nanofibers}$ functionalized with reduced graphene oxide nanosheets. ACS Applied Materials \& Interfaces. 6, (2), 2588-2597 (2014).

43. Aylikci, B. U., Colak, H. Halitosis: From diagnosis to management. Journal of Natural Science, Biology, and Medicine. 4, 14-23 (2013).

44. Goldberg, S., et al. Cadaverine as a putative component of oral malodor. Journal of Dental Research. 73, 1168-1172 (1994).

45. Kanu, A. B., et al. Rapid screening of 2-[18F]-fluoro-2-deoxy-D-glucose infusions for volatile organic compound contaminants by solid phase microextraction with gas chromatography-selective ion monitoring mass spectrometry SPME-GC-SIMMS). Applied Radiation and Isotopes : Including Data, Instrumentation and Methods for Use in Agriculture, Industry. 58, 193-200 (2003). 
46. Han, D. H., Lee, S. M., Lee, J. G., Kim, Y. J., Kim, J. B. Association between viral hepatitis B infection and halitosis. Acta Odontologica Scandinavica. 72, 274-282 (2014).

47. Awano, S., et al. Relationship between volatile sulfur compounds in mouth air and systemic disease. Journal of Breath Research. 2, 017012 (2008).

48. Porter, S. R. Diet and halitosis. Current Opinion in Clinical Nutrition and Metabolic. 14, 463-468 (2011).

49. Sekirov, I., Russell, S. L., Antunes, L. C., Finlay, B. B. Gut microbiota in health and disease. Physiological Reviews. 90, (3), 859-904 (2010).

50. Di Cerbo, A., Canello, S., Guidetti, G., Laurino, C., Palmieri, B. Unusual antibiotic presence in gym trained subjects with food intolerance; a case report. Nutr Hosp. 30, (2), 395-398 (2014).

51. Freeman, L. M., Chandler, M. L., Hamper, B. A., Weeth, L. P. Current knowledge about the risks and benefits of raw meat-based diets for dogs and cats. J Am Vet Med Assoc. 243, (11), 243-2411 (2013). 